\title{
JUURNAL.RU
}

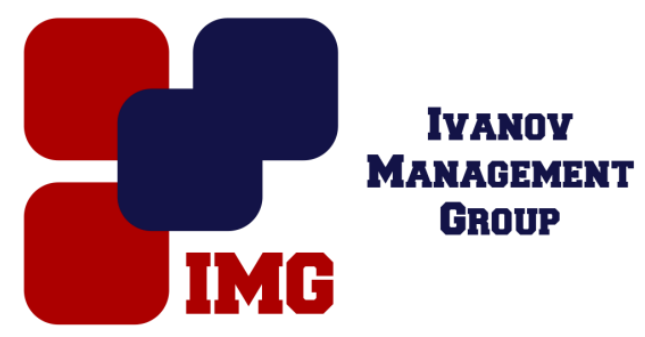

Максимович Л.Г., Ковалева Ю.Л. МБУЗ ЦРБ Октябрьского района Ростовской области Россия

doi: $10.18411 / 1 \mathrm{j}-31-05-2017-38$

idsp 000001:1j-31-05-2017-38

\section{Уменышение выраженности болевого синдрома после тонзиллэктомии}

Двусторонняя тонзиллэктомия - одна из самых распространенных операций в оториноларингологической практике. В последние годы это вмешательство все чаще выполняется у детей и подростков [1], что обусловлено ростом числа постстрептококковых осложнений [2, 3], в том числе, паратонзиллярных абсцессов у больных младших возрастных групп.

Одна из серьезных проблем детской хирургии - послеоперационное обезболивание. Боль при глотании после двусторонней тонзиллэктомии возникает вследствие развития реактивного послеоперационного воспаления [4], сохраняется в течение нескольких дней и может не только существенно снизить качество жизни больного, но и привести к значительным нарушениям гомеостаза вследствие отказа ребенка от приема пищи и жидкости. Вместе с тем, следует отметить наличие ограничений при назначении анальгетиков, в частности, нестероидных противовоспалительных препаратов, ввиду повышения риска послеоперационных ранних и поздних кровотечений [5]. Все это является основанием для поиска новых методов предупреждения и лечения послеоперационной боли при операциях на лимфокольце глотки.

В литературе имеются указания на возможность уменьшения боли после тонзиллэктомии при интраоперационном применении фибринового клея $[6,7]$, охлаждении миндаликовых ниш [8], ушивании небных дужек [9].

Целью нашего исследования было изучение влияния ушивания небных дужек на выраженность послеоперационной боли и частоту послеоперационного кровотечения у больных, перенесших двустороннюю тонзиллэктомию. 
Материал и методы исследования. В исследование было включено 36 больных, подвергнутых двусторонней тонзиллэктомии, среди которых было 8 детей в возрасте от 10 до 14 лет и 28 взрослых от 19 до 32 лет. Показаниями для операции было наличие хронического декомпенсированного тонзиллита. Критериями исключения было наличие сердечно-сосудистой, суставной и почечной патологии, наличие паратонзиллярного абсцесса в остром периоде, а также прием каких-либо лекарственных препаратов на регулярной основе.

Больные были разделены на 2 группы, по 18 человек в каждой. Больным первой группы в конце произведено ушивание миндаликовых ниш, вторая группа была контрольной. Фиксировали потребность в аналгетиках, сроки перехода на обычную пищу и наличие ранних и поздних послеоперационных кровотечений в течение 2 недель. Выраженность боли при глотании оценивали с применением визуально-аналоговой шкалы (ВАШ) по 10-бальной шкале в 1, 2, 4 и 7 день после операции. Результаты обрабатывали статистическими методами с использованием критерия $\chi 2$. Разница считалась достоверной при $\mathrm{p}<0,05$.

Результаты и их обсуждение.

Позднее послеоперационное кровотечение наблюдалось у 1 больного из контрольной группы $(\mathrm{p}=0,85)$, различия между группами недостоверны.

Достоверной разницы в степени выраженности послеоперационной боли $(\mathrm{p}=0,79)$ и количестве потребляемых больным аналгетиков в первую неделю после операции $(\mathrm{p}=0,69)$ не выявлено.

Поиски средств уменьшения боли после тонзиллэктомии не прекращаются на протяжении нескольких десятилетий. С этой целью использовали интра- и послеоперационное назначение антибиотиков [10], стероидов [11], гомеопатических средств [12], фибринового клея. Данные об эффективности аппликации фибринового клея весьма противоречивы. Так, М.H. Stevens et al. [7] отметили более короткие сроки реабилитации больных после хирургического вмешательства при применении фибринового клея, a M. Vaiman et al. [13] подтвердили этот эффект с помощью поверхностной электромиографии. В то же время S.J. Stoeckli et al. [14], N. Segal et al. [15] не отметили достоверных различий в течении послеоперационного периода у больных с использованием фибринового клея по сравнению с контрольной группой. Также противоречивы данные о влиянии ушивания миндаликовых ниш [16].

По нашим данным, ушивание миндаликовых ниш во время выполнения двусторонней тонзиллэктомии не привело к уменьшению выраженности боли 
при глотании в послеоперационном периоде. Достоверных данных о снижении риска послеоперационных кровотечений при применении данной методики также не получено.

$* * *$

1. Бойко Н.В., Локшина Л.С., Сорока Г.Г., Бриж Ю.В., Сулина Н.Ю. Изменение подходов к лечению хронического тонзиллита в детском возрасте по материалам Ростовской ЛОР клиники. Вестник оторинолар. 2012; 5: 226.

2. Белов Б.С. Рациональная антимикробная терапия А-стрептококкового тонзиллита основа первичной профилактики ревматической лихорадки. Соврем. ревмат. 2011. № 1. C. $13-22$.

3. Власова Т.М. Бойко Н.В., Рост числа постстрептококковых осложнений у больных хроническим тонзиллитом. Российская оториноларингология, 2015, № S1, С. 45-47.

4. Бойко Н.В., Бачурина А.С., Оксенюк О.С., Колмакова Т.С. Лечение послеоперационного воспаления после тонзиллэктомии у детей. Педиатрия. Журнал им. Г.Н. Сперанского. 2016, т. 95, № 1. С. 93-96.

5. Бойко Н.В., Бачурина А.С., Жданов А.И. Профилактика послеоперационных кровотечений при аденотомии. Рос. ринология 2015; 23 ( 2): 26-30.

6. Gross C.W., Gallagher R., Schlosser R.J., Burks S.G., Flanagan H.L., Mintz P.D. Autologous fibrin sealant reduces pain after tonsillectomy, Laryngoscope. 2001. Vol. 111. N 2. P. 259263.

7. Stevens M.H., Stevens D.C. Pain reduction by fibrin sealant in older children and adult tonsillectomy, Laryngoscope. 2005. Vol. 115, N 6. P. 1093-1096.

8. Shin J.M., Byun J.B., Baek B.J., Lee J.Y. Effect of cold-water cooling of tonsillar fossa and pharyngeal mucosa on post-tonsillectomy pain. Am J of Otolaryngol. 2014. V. 35, № 3. P. 353-356.

9. Genc E., Hanci D., Ergin N.T., Dal T. Can mucosal sealing reduce tonsillectomy pain? Int. J. Pediatr. Otorhinolaryngol. 2006. Vol. 70. P. 725-730..

10. Dhiwakar M., Eng C.Y., Selvaraj S., Mc Kerrow W.S. Antibiotics to improve recovery following tonsillectomy: a systematic review. Otolaryngol Head Neck Surg. 2006. Vol. 134, N 3. P. 357-364.

11. Al-Shehri A.M. Steroid therapy for post-tonsillectomy symptoms in adults: a randomized, placebo-controlled study. Ann Saudi Med. 2004. Vol. 24. N 5). P. 365-367.

12. Robertson A., Suryanarayanan R., Banerjee A. Homeopathic Arnica montana for posttonsillectomy analgesia: a randomized placebo control trial. Homeopathy. 2007. Vol. 96, N 1. P. $17-21$.

13. Vaiman M., Krakovski D., Gavriel H. Fibrin sealant reduces pain after tonsillectomy: prospective randomized study. Ann Otol Rhinol Laryngol. 2006. Vol. 115, 7. P. 483-489.

14. Stoeckli S.J., Moe K.S., Huber A., Schmid S. A prospective randomized double-blind trial of fibrin glue for pain and bleeding after tonsillectomy, Laryngoscope. 1999. Vol. 109, N4. P. $652-655$.

15. Segal N., Puterman M., Rotem E., Niv A., Kaplan D., Kraus M., Brenner H., Nash M., Tal A., Leiberman A. A prospective randomized double-blind trial of fibrin glue for reducing pain and bleeding after tonsillectomy. Int. J. of Pediatric Otorhinolar. 2008. Vol. 72. P. 469473.

16. Matt B.H., Krol B.J., Ding Y., Juliar B.E. Effect of tonsillar fossa closure on postoperative pain and bleeding risk after tonsillectomy. Int. J. of Pediatric Otorhinolar. 2012. Vol. 76. P. $1799-1805$. 